\title{
Invasion of the leptomeninges by tumour: the differential diagnosis from tuberculous meningitis
}

\author{
I. E. HUGHES, ${ }^{1}$ J. HUME ADAMS ${ }^{2}$ AND R. C. ILBERT \\ From the Military Hospital, Wheatley, and the Tuberculous Meningitis Unit, \\ United Oxford Hospitals
}

Published accounts of tuberculous meningitis usually include intracranial tumour in the differential diagnosis. However, the two conditions are only likely to be confused when tuberculous meningitis is complicated by a tuberculoma or when there is diffuse infiltration of the subarachnoid space by malignant cells. As the latter causes an increase in both the cell and protein content of the cerebrospinal fluid, the resemblance to tuberculous meningitis may be striking (Russell, 1939) since signs and symptoms of raised intracranial pressure and of meningeal irritation, together with a wide variety of focal neurological signs, are common to both conditions.

Diffuse infiltration of the leptomeninges by tumour is not excessively rare, as Polmeteer and Kernohan (1947) described 42 cases of meningeal gliomatosis while Fischer-Williams, Bosanquet, and Daniel (1955) referred to more than 50 cases of meningeal carcinomatosis. Such cases are likely to be referred to specialized neurological or neurosurgical centres, and during a period of two years, at a time when we were working with the Tuberculous Meningitis Unit of the United Oxford Hospitals, we encountered two cases of meningeal gliomatosis and two of meningeal carcinomatosis. To these we are permitted, through the courtesy of Mr. Wylie McKissock, to add a third case of meningeal carcinomatosis.

In all five cases tuberculous meningitis was at some time suspected and it was only after intensive investigation, including contrast encephalography, cytological examination of the cerebrospinal fluid, and the bromide test, that the correct diagnosis was established in three before death. These cases are reported here because early and correct differentiation of the two conditions is of considerable importance: tuberculous meningitis is eminently treatable and radiotherapy may relieve symptoms in

'Present address: Department of Neurology, Churchill Hospital, Oxford.

'Present address: The University and Western Infirmary, Glasgow, W.1. diffuse involvement of the leptomeninges by tumour (Heathfield and Williams, 1956). It is also of some theoretical interest as well as of practical importance that the increase in the bromide ratio in all five cases was of the same order as that observed in tuberculous meningitis (Taylor, Smith, and Hunter, 1954).

\section{CASE REPORTS}

CASE 1 (W.M.H. N/1063) A.J.B., a National Serviceman aged 19, was transferred to Wheatley Military Hospital on 15 January 1956, with a presumptive diagnosis of tuberculous meningitis. Two siblings had had pulmonary tuberculosis, but the patient himself had always been exceptionally healthy and athletic until four weeks before admission when he began to have attacks of pain behind the eyes. The headache grew steadily worse, he lost his appetite, became nauseated and began to vomit, and later still became drowsy and felt extremely ill. On 10 January 1956 he was admitted to the Military Hospital, Colchester.

On admission he was drowsy although rousable. He had no fever and his pulse was 60 . His neck was a little stiff and Kernig's sign was positive. All the tendon reflexes were depressed but there were no focal neurological signs other than a mild right facial weakness. Lumbar puncture yielded a faintly cloudy fluid under normal pressure and contained 56 white cells per c.mm. of which $50 \%$ were polymorphonuclear leucocytes; the protein was $130 \mathrm{mg}$. per $100 \mathrm{ml}$. and the sugar $52 \mathrm{mg}$. per $100 \mathrm{ml}$. No organisms were seen on a Ziehl-Neelsen stained film. The blood count was normal. A presumptive diagnosis of tuberculous meningitis was made and full anti-tuberculous treatment was begun at once. Three days later he was transferred to Wheatley under the care of Dr. Honor Smith.

On arrival his condition was essentially unchanged. Though drowsy, he could easily be roused and was then perfectly lucid and capable of giving a full and detailed history. He was apyrexial but meningitic, and, apart from the knee and ankle jerks being now unobtainable, there were no other abnormalities in the nervous system. Radiography of the chest was normal, the E.S.R. was 4 mm. per hour (Westergren), and the Mantoux test was positive at 1 in 1,000 . At lumbar puncture the cerebrospinal fluid was found to be under normal pressure and to 
contain 38 white cells ( $8 \%$ polymorphonuclear leucocytes) per c.mm., the protein was $113 \mathrm{mg}$. per $100 \mathrm{ml}$. and the sugar $32 \mathrm{mg}$. per $100 \mathrm{ml}$. The cisternal cerebrospinal fluid contained 22 white cells per c.mm., the protein was $54 \mathrm{mg}$. per $100 \mathrm{ml}$. and sugar $32 \mathrm{mg}$. per $100 \mathrm{ml}$. No acid-fast bacilli were identified in either lumbar or cisternal cerebrospinal fluid. The bromide ratio was 0.90 for lumbar and $\mathbf{0 . 5 2}$ for the cisternal cerebrospinal fluid.

It was clear that the patient was suffering from subacute meningitis. In view of the family history of tuberculosis, the insidious onset of the illness, the change in the cells, protein and sugar content of the cerebrospinal fluid, and the high bromide ratio it was thought that in all probability this was tuberculous, although absence of fever and the preservation of mental clarity in someone so obviously ill were noted as very unusual. Anti-tuberculous treatment with daily intrathecal and systemic streptomycin and isonicotinic acid hydrazide was continued.

Over the next few days there was little change in the patient's condition or in the cerebrospinal fluid; the cell counts ranged between 3 and 264 per c.mm., the protein content remained high and the sugar content was persistently low. Every specimen of cerebrospinal fluid was examined for Mycobacterium tuberculosis but with negative result. On the twelfth day in hospital both lateral ventricles were tapped through frontal burr holes. The intraventricular pressure was normal and the cerebrospinal fluid contained $\mathbf{4 0}$ lymphocytes per c.mm. and a protein level of $45 \mathrm{mg}$. per $100 \mathrm{ml}$.: no tubercle bacilli were found in the cerebrospinal fluid. Three days later lumbar air encephalography was performed. This showed mild symmetrical dilatation of the lateral ventricles and poor filling of the anterior basal cisterns, characteristic findings in tuberculous meningitis (Acheson and Smith, 1958).

The patient tolerated these procedures well, but during the third week in hospital the intracranial pressure began to rise and he developed papilloedema and bilateral external rectus paralysis. Cortisone and, later, intrathecal tuberculin, were without effect and frequent ventricular taps were necessary to control the ever increasing pressure. On his twenty-ninth day in hospital he became totally blind and over the next few days the right ninth and tenth cranial nerves became paralysed. Thereafter he was fed by tube and required frequent pharyngeal suction.

On the thirty-third hospital day malignant cells were identified in the cerebrospinal fluid by Dr. A. Spriggs. Anti-tuberculous treatment was therefore stopped and although no evidence of a primary tumour had been found a course of total body irradiation was begun by Dr. F. Ellis. Three days later he died in coma after an illness lasting 44 days.

Pathology At necropsy the only abnormalities were those in the nervous system where a typical glioblastoma multiforme, measuring about $2.5 \mathrm{~cm}$. in diameter, was found in the infero-medial part of the left frontal lobe. The tumour had replaced part of the adjacent cortex and had obviously spread to the subarachnoid space but, apart from a grey opaque area on the inferior aspect of the left cerebellar hemisphere, the leptomeninges over the

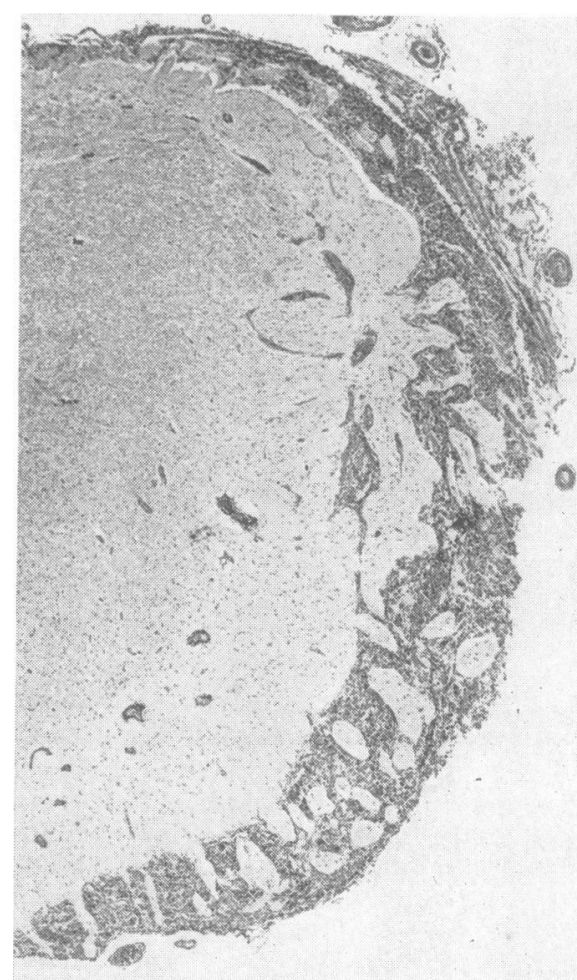

FIG. 1. Case 1, optic nerve. The nerve is cuffed by tumo cells which are extending along perivascular spaces (Haematoxylin and eosin $\times 26$.)

rest of the brain and spinal cord were normal. Two nodules of grey tumour were found in the lumbar part of the spinal cord.

Microscopical examination confirmed that the tumour was a glioblastoma multiforme and sections of represent- ฏँ ative areas of the cerebral cortex, cerebellum, brain-stem, $\mathbb{D}$ spinal cord, and optic nerves (Fig. 1) all showed diffuse involvement of the subarachnoid space by tumour.

CASE 2 L.D., a storeman aged 21, was admitted to the Royal Hampshire County Hospital, Winchester, on 28 March 1957 with a three months' history of increasing headache, vomiting, and loss of weight with, more recently, increasing weakness of the left leg. He was found to have moderate neck stiffness, papilloedema, and a right homonymous hemianopia. The lumbar cerebrospinal fluid contained 125 lymphocytes per c. mm.; the protein was $120 \mathrm{mg}$., and the sugar $50 \mathrm{mg} . / 100 \mathrm{ml}$., but no organisms were seen on either Ziehl-Neelsen or Gram- 울 stained films. A presumptive diagnosis of tuberculous meningitis was made and appropriate chemotherapy begun. In spite of this he became more drowsy and repeated lumbar puncture showed that the intracranial $N$ pressure was still high. Accordingly on 12 April 1957 he was transferred to the Military Hospital, Wheatley, under the care of Dr. Honor Smith. 
On admission he was drowsy but, like the previous patient, when roused he was perfectly lucid and could give a good, accurate history. He had no fever and his pulse was 70. Examination showed moderate neck stiffness, bilateral papilloedema and a complete right oculomotor palsy, but the homonymous hemianopia was not confirmed. He had a left hemiparesis without sensory loss and all the tendon reflexes were diminished. No abnormality was found outside the nervous system. The Mantoux test was positive at 1 in 1,000 and radiography of the skull and chest was normal. At lumbar puncture the cerebrospinal fluid was under a pressure of more than 300 $\mathrm{mm}$. of water but the composition had not changed significantly since the first examination. The bromide ratio was $0 \cdot 98$. Ventricular needling through bifrontal burr holes showed that the lateral ventricles were symmetrically placed and moderately dilated. An attempt at ventriculography failed, and on lumbar pneumoencephalography the flow of air over the cerebral hemispheres was obstructed at the level of the posterior clinoid processes whilst no air entered the ventricular system.

In view of these findings tuberculous meningitis was thought to be the most likely diagnosis and the chemotherapy was therefore continued. However, because of the afebrile course and the mental clarity, the possibility of infiltration of the leptomeninges by tumour was kept in mind and every specimen of cerebrospinal fluid was examined for malignant cells, as well as for tubercle bacilli, but with negative results. Over the next day or two there was a transient improvement in the hemiparesis but the headache became increasingly severe and was relieved only by lumbar puncture. One week after admission he died suddenly in apnoea and on agonal ventricular puncture the pressure of the cerebrospinal fluid was found to be $500 \mathrm{~mm}$. of water.

Pathology At necropsy, abnormalities were again confined to the nervous system. On the surface of both cerebral hemispheres there were many flat grey plaques measuring up to $5 \mathrm{~mm}$. in diameter and there was diffuse thickening of the meninges at the base of the brain and over the cerebellum. Sections of the brain showed a large, solid, white tumour in the medial part of the right temporal lobe. The spinal cord was not removed.

Microscopical examination showed that the tumour was a glioblastoma multiforme and that there was diffuse infiltration of the subarachnoid space by tumour cells.

Both these patients were of the age that has been commonest in the Oxford series of tuberculous meningitis. In the next three cases the patients were older and, although tuberculous meningitis is not excessively rare in middle age, this, together with certain other considerations made carcinomatosis of the meninges appear the more probable diagnosis. Nevertheless the likeness to tuberculous meningitis was sufficiently close for chemotherapy to be begun pending confirmation of malignant disease.

CASE 3 E.G.T., a man of 47, was admitted to the Royal South Hants Hospital, Southampton, on 17 August 1957 under the care of Dr. Robertson with a 10-week history of malaise, nausea, and anorexia. This was followed by increasingly severe occipital and frontal headache. One week before admission he had complained of diplopia and rapidly failing vision. On admission he was found to have marked neck rigidity although Kernig's sign was negative. He was so nearly blind that the visual acuity in the right eye was reduced to J16 and in the left eye to finger counting. The right plantar response was extensor. The lumbar cerebrospinal fluid contained 118 white cells per c.mm., a third of which were large endothelial cells in clumps; the protein was $80 \mathrm{mg}$. and the sugar $58 \mathrm{mg}$. per $100 \mathrm{ml}$. The bromide ratio was $0 \cdot 83$. Despite the fact that the large cells were suspected of being malignant, it was thought that the possibility of tuberculous meningitis could not be excluded and anti-tuberculous chemotherapy was accordingly begun. Further lumbar punctures showed a steady increase in protein content and cell count and on 29 August 1957 he was transferred to Atkinson Morley's Hospital under the care of $\mathrm{Mr}$. McKissock.

On arrival he was alert, orientated, and rather apprehensive. Examination showed marked neck stiffness, bilateral papilloedema, and paralysis of the left facial and hypoglossal nerves. The limbs were hypertonic and ataxic and there was a definite right hemiparesis. The tendon reflexes were all depressed and the plantar re-

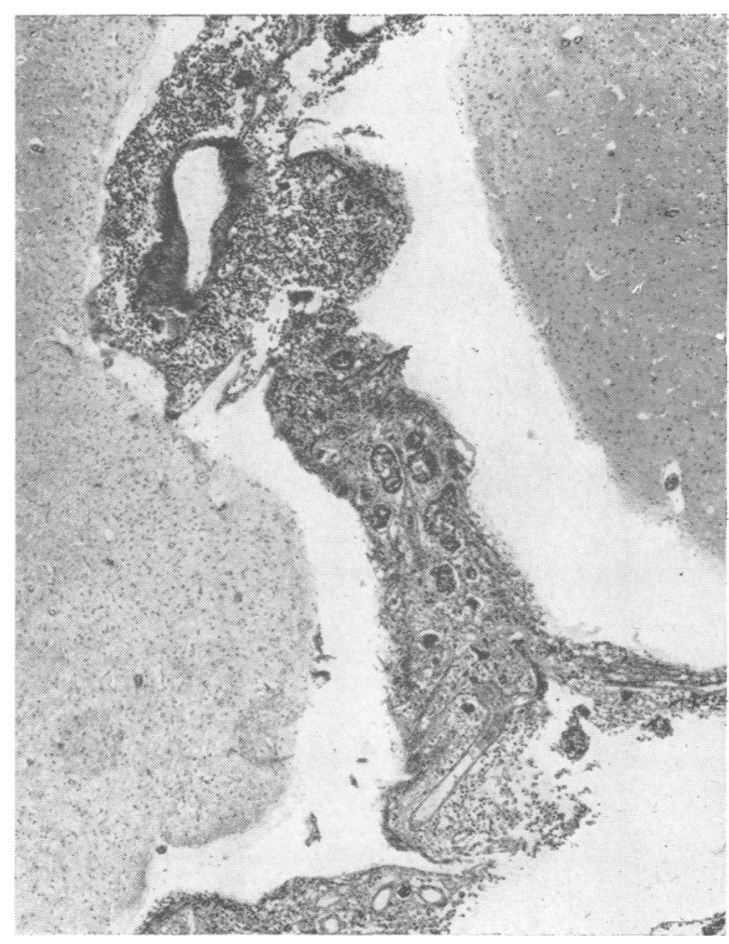

FIG. 2. Case 3, cerebral hemisphere. There are numerous small foci of adenocarcinoma in the leptomeninges. (Haematoxylin and van Gieson $\times 39$.) 
sponses were extensor. On the evening of admission needling of the right lateral ventricle showed that the pressure of the cerebrospinal fluid was greatly increased. No displacement of the ventricular system was seen on contrast ventriculography. After the two days during which a ventricular drain kept pressure under control his condition deteriorated and he died on 19 September 1957.

Pathology At necropsy, this man was found to have an adenocarcinoma in the tail of the pancreas: there was extensive local infiltration into the mesentery and adjacent lymph nodes and there were numerous small subcapsular metastases in the liver. Examination of the brain showed that there was diffuse opacity of the leptomeninges, most marked over the vertex and on the lateral surfaces of the cerebral hemispheres and least obvious at the base. Dissection of the brain was limited to one horizontal cut: this revealed no abnormalities in the brain or ventricles. The spinal cord was not removed.

Microscopical examination of sections from the cerebral hemispheres (Fig. 2), optic nerves, and cervical cord all showed diffuse infiltration of the subarachnoid space by adenocarcinoma. Spread of malignant cells along the perivascular spaces was prominent and extended into the subcortical white matter in the cerebrum.

CASE 4 (R.I. 259698) F.B., a woman of 49, was admitted to Northampton General Hospital on 20 August 1958 under Dr. McQuaide. She complained of increasing pain

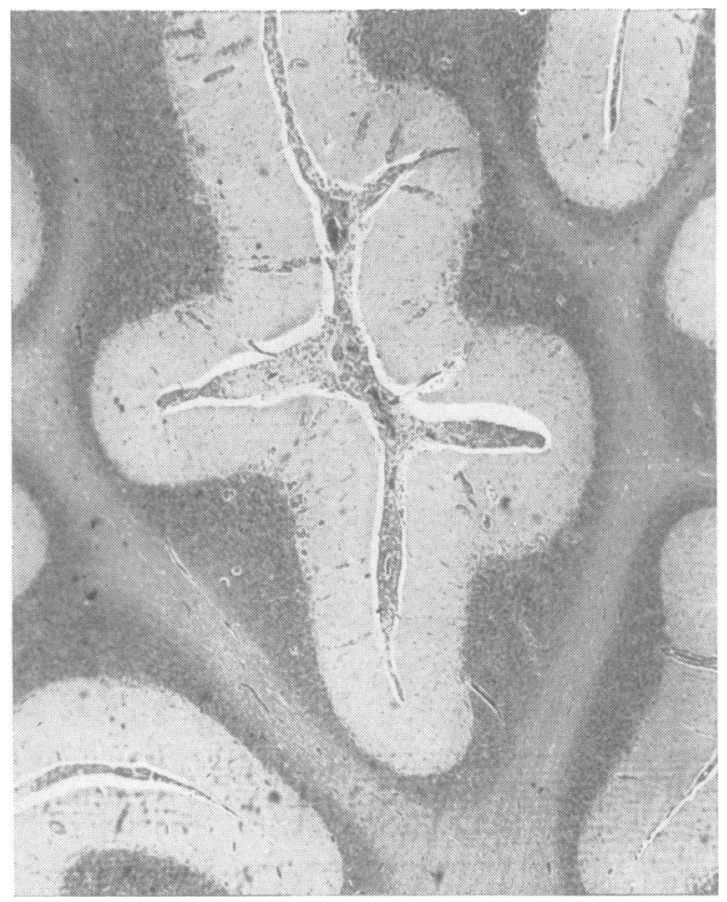

FIG. 3. Case 4, cerebellum. The subarachnoid space between the folia contains tumour cells which also extend along perivascular spaces. (Haematoxylin and eosin $\times 18$.) in the back of both legs and in the neck and admitted that $\bar{Z}$ for the previous three months she had been generally unwell with anorexia, nausea, and loss of weight. There was a strong family history of tuberculosis and she had recently refused $x$-ray examination as a contact. On ${ }^{\Theta}$ examination she was apyrexial and the only abnormal ${ }_{0}$ physical signs were intense meningism and sluggish tendon reflexes. Lumbar puncture revealed a fluid under high pressure which contained 210 white cells per c.mm., $\stackrel{\overrightarrow{2}}{\overrightarrow{2}}$ of which the majority were polymorphonuclear leucocy-. tes; the protein was $211 \mathrm{mg}$. per $100 \mathrm{ml}$. and the sugar $\overrightarrow{\overline{\vec{N}}}$ content was reduced. She was treated with penicillin and $\stackrel{\oplus}{\rightarrow}$ transferred to the Radcliffe Infirmary, Oxford, under the care of Mr. Pennybacker.

Though still apyrexial and fully alert, it was obvious $\frac{\overline{\bar{S}}}{\vec{T}}$ that she was seriously ill. The neck was held rigidly in $\stackrel{\varnothing}{\complement}$ moderate extension and even at rest she complained that it hurt, while any movement of her head was acutely $\infty$ painful. A divergent squint and generalized hyporeflexia $\vec{\circ}$ were the only other abnormal signs. The lumbar cerebrospinal fluid contained 750 white cells per c.mm., of which $\vec{\omega}$ the great majority were polymorphonuclear leucocytes; the protein was $400 \mathrm{mg}$. per $100 \mathrm{ml}$., the sugar content was diminished, and the bromide ratio was $1 \cdot 24$. Radio-? graphy of the chest was normal. Ventriculography $\stackrel{\sim}{]}$ showed no abnormality either of the ventricular system of of the basal cisterns. Radiography of the cervical sping, however, suggested a defect in the lamina of the thire

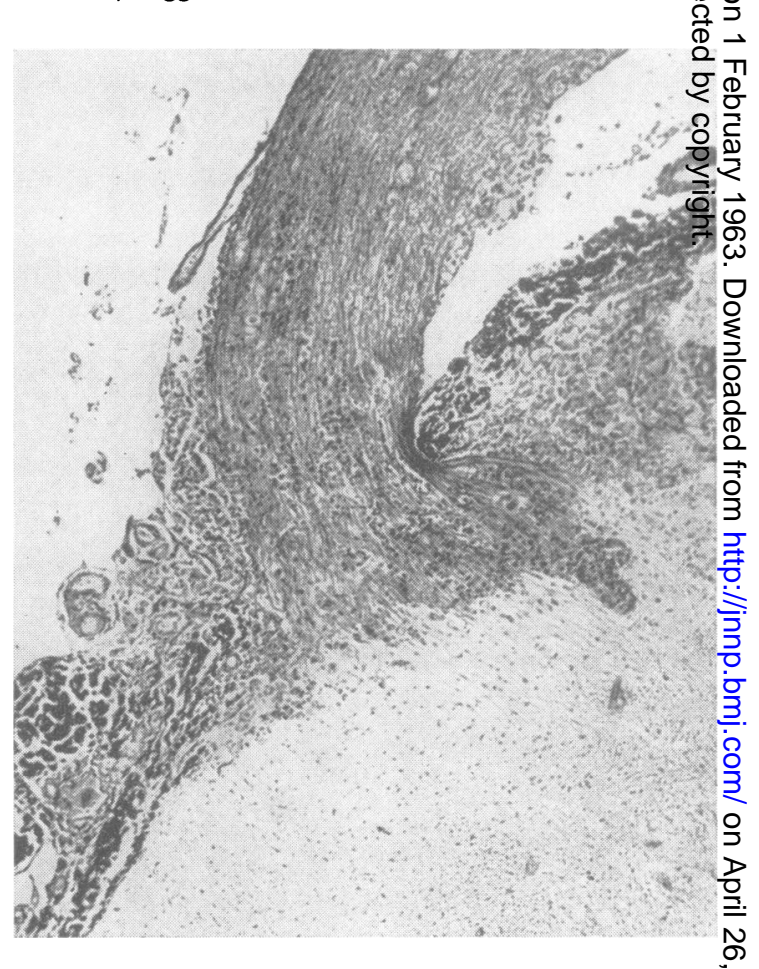

FIG. 4. Case 4, spinal cord. A thoracic dorsal nerve root is $\mathrm{N}$ infiltrated by carcinoma. (Haematoxylin and van Gieson $\times$ 39.) 
cervical vertebra. In view of this and the polymorphonuclear leucocytosis in the cerebrospinal fluid, it was decided that the possibility of a Brodie's abscess giving rise to a low-grade purulent meningitis should be excluded by operation but on cervical laminectomy no lesion was found. This being so, the diagnosis was thought most probably to be carcinomatosis of the meninges but, since no evidence of a primary tumour was found and since the possibility of tuberculous meningitis could not be excluded, treatment with streptomycin and I.N.A.H. was begun and each specimen of cerebrospinal fluid searched for malignant cells as well as for tubercle bacilli. Two days after operation malignant cells were identified in the cerebrospinal fluid. Chemotherapy was therefore withheld and nine days later the patient died.

Pathology At necropsy this woman was found to have an adenocarcinoma of the stomach extending from the pylorus to within $5 \mathrm{~cm}$. of the cardia. No other abnormalities were found outside the nervous system. Apart from a well-healed surgical incision in the meninges over the upper cervical spinal cord, the brain and spinal cord were of entirely normal appearance externally and on section.

Microscopical examination of representative blocks from the cerebral hemispheres, cerebellum (Fig. 3), optic nerves, brain-stem, and spinal cord all showed diffuse infiltration of the subarachnoid space by adenocarcinoma. Spread along perivascular spaces was again conspicuous. In this case malignant cells had also infiltrated into several of the dorsal roots of the spinal nerves (Fig. 4). Several small clumps of carcinoma cells were seen in the choroid plexus of the lateral ventricles but malignant cells were not seen on the ependyma.

CASE 5 (U.O.H. 226450) W.C., a man of 49, was readmitted to the Churchill Hospital, Oxford, under the care of Mr. J. S. Calnan for re-constructive surgery after radical excision of a radio-insensitive carcinoma of the right cheek two years earler. Microscopic examination of the operation specimen had suggested that the lesion was a poorly differentiated adenocarcinoma arising from a sweat gland, parotid gland, or lachrymal gland. Repeated examination during the interval had revealed no sign of any local or distant recurrence. For six weeks he had been worried by pain in the back which had begun when gardening and which was made worse by bending his neck. At the same time he lost his appetite and developed a cough. Two days before admission he had vomited.

On examination he looked well, he had no fever, and mentally he was perfectly lucid. His neck, however, was very stiff and Kernig's sign was positive. The operative defect was clean and healthy, there were no signs of local recurrence, and the regional lymph nodes were not enlarged. None of the tendon reflexes could be obtained but, apart from some doubtful impairment of sensation below the umbilicus, there were no other abnormal signs. Lumbar puncture revealed a fluid under normal pressure containing 292 white cells per c.mm., of which 73 were polymorphonuclear leucocytes, 186 lymphocytes, and 33 macrophages; the protein was $528 \mathrm{mg}$. per $100 \mathrm{ml}$. and the sugar content slightly reduced. The bromide ratio was 0.89 .

Because of the lack of fever, the normal mental state, and the areflexia, a diagnosis of meningeal carcinoma was made but, pending identification of malignant cells in the cerebrospinal fluid, antituberculous therapy was begun. Two days later one malignant cell was seen and further cells were found $\mathbf{1 0}$ days later. Chemotherapy was therefore stopped. He deteriorated slowly and died of bronchopneumonia five weeks after his admission.

Pathology At necropsy the only significant abnormalities were those in the nervous system and at the original operation site in the face where the skin was infiltrated by poorly differentiated carcinoma. The only external abnormality noted on examination of the brain was a cuff of firm pale tissue around the origin of the right trigeminal nerve. However, there were many small grey plaques around the spinal nerve roots, particularly in the cauda equina. Sections of the brain and spinal cord were of normal appearance.

Microscopical examination showed that carcinomatosis of the leptomeninges was less extensive than in the previous cases. The root of the right trigeminal nerve and the Gasserian ganglion were infiltrated by tumour, and malignant cells were seen in the subarachnoid space over the optic chiasm, in the interpeduncular fossa and around the spinal cord where many anterior and posterior nerve roots were infiltrated by tumour. Malignant cells were not seen in any of the numerous blocks of cerebral hemispheres or cerebellum examined nor were they seen in the choroid plexus or in the ventricles.

\section{DISCUSSION AND CONCLUSIONS}

While it is now generally accepted that the clinical picture of carcinomatosis of the leptomeninges may be very similar to that of tuberculous meningitis, cases 1 and 2 show that the resemblance may be even closer in gliomatosis of the leptomeninges. Moreover, this resemblance extends not only to the changes in the cerebrospinal fluid but also to the results of those special investigations which are otherwise most helpful in distinguishing tuberculous meningitis from other varieties of so-called 'lymphocytic' meningitis, namely pneumoencephalography and the bromide test. Thus the moderate pleocytosis with a high percentage of 'round' cells, the marked rise in protein content in comparison with the cell count, and the significant fall in the sugar content that were found in these cases are all characteristic of tuberculous meningitis, as are the occlusion of the more anterior basal cisterns seen on pneumoencephalography and the bromide ratio of near unity.

In view of the diagnostic problem arising from these similarities, any consistent points of difference become important. It is therefore worth noting that in all five cases the course of the illness was apyrexial, that the patients remained fully conscious and rational even when obviously very ill, and that the 
tendon reflexes were all either diminished or absent. Any one of these features is rare in tuberculous meningitis while their combination must be virtually unknown.

Just as in tuberculous meningitis final proof of the diagnosis rests on identification of tubercle bacilli in the cerebrospinal fluid, so in carcinomatosis or gliomatosis of the meninges it rests on the recognition of malignant cells. Techniques for demonstrating malignant cells in the cerebrospinal fluid have received much attention in recent years and are now capable of yielding positive results in a high percentage of cases (Spriggs, 1954; McMenemey and Cumings, 1959; Marks and Marrack, 1960). Our cases confirm the value of this procedure as, in three, malignant cells were successfully identified.

In attempting to correlate the clinical with the pathological findings it becomes clear that several problems remain to be answered. Thus Berg (1953) noted that generalized hyporeflexia was common in carcinomatosis of the meninges and he attributed this to infiltration of the spinal nerve roots by tumour cells. In two of our three cases in which the spinal cords were examined the spinal nerve roots were indeed heavily infiltrated. It is, however, not clear why this should merely diminish or abolish the tendon reflexes without causing any obvious paresis or sensory loss. The rapid onset of visual failure in other cases of carcinomatosis of the meninges has been attributed to cuffing of the optic nerves by tumour cells (Fischer-Williams et al., 1955; Heathfield and Williams, 1956). Yet only two of our patients went blind although the optic nerves in all five were completely surrounded by tumour.

The cause of the marked and consistent elevation of the bromide ratio in diffuse infiltration of the meninges by malignant cells is also obscure. Determination of the bromide ratio is the best clinical method at present available for estimating the permeability of the blood cerebrospinal fluid barrier (Hunter, Smith, and Taylor, 1954) and the only other conditions we know of in which the increase in barrier permeability is as constant and of the same order are the intrathecal tuberculin reaction and tuberculous meningitis (Smith, Taylor, and Hunter, 1955). As there is now good reason to believe that the changes in the cerebrospinal fluid in tuberculous meningitis are simply the manifestations of repeated spontaneous intrathecal tuberculin reactions (Taylor, Smith, and Vollum, 1955), it appears that the change in barrier permeability is in some way a property of an allergic reaction of the meninges of the 'delayed' or 'tuberculin-type' variety. This raises the interesting possibility that some such allergic mechanism may be at work in carcinomatosis and gliomatosis of the meninges. This hypothesis is compatible by analogy with the relationship between tuberculomas and tuberculous meningitis, as tumours of the nervous system do not seriously affect the bromide ratio unless the subarachnoid space becomes diffusely infiltrated by malignant cells. It would also 0 account for the other changes in the cerebrospinal fluid which are so like those in tuberculous menin- $\frac{\text { S }}{S}$ gitis. Finally, if tumour tissue can become antigenic, this might be the explanation of the intense, localized oedema that sometimes surrounds brain $\underset{\Rightarrow}{\Rightarrow}$ tumours.

In conclusion, it is clear that from time to time $\frac{\overline{ }}{\overline{0}}$ cases are seen in which the diagnosis remains $\vec{\Phi}$ uncertain until either tubercle bacilli or malignant $\propto$ cells are identified in the cerebrospinal fluid. In such के cases full anti-tuberculous treatment must be given $\vec{\circ}$ pending confirmation of the diagnosis. In this way no valuable time will be lost if in the end the patient $\vec{\omega}$ proves to have tuberculous meningitis. At the present time malignant infiltration of the meninges is always a fatal disease, although radiotherapy may some-iv times alleviate symptoms and prolong life (Heath- $?$ field and Williams, 1956). In tuberculous meningiti, $\vec{\infty}$ on the other hand, delay in treatment may only to easily make the whole difference between a full and permanent recovery and disastrous disability $\mathrm{Br}_{\mathrm{r}}^{-}$ death.

\section{SUMMARY}

The clinical and pathological features of five cases of meningitis due to invasion of the meninges by tumour are described.

The differential diagnosis from tuberculous meningitis is discussed. The triad of mental clarity, lack of pyrexia, and hyporeflexia are presented as strong $\frac{\mathbb{Q}}{\mathbb{Q}}$ evidence of a neoplastic meningitis.

It is suggested that the changes in the cerebro- $\overline{0}$ spinal fluid and the alteration in permeability of the blood cerebrospinal fluid barrier might represent an allergic response to the neoplastic cells. This is considered to be analogous to the intrathecal tuberculin reaction.

We wish to thank Dr. Honor Smith for all her con structive criticism and advice, and for permission to refer to her cases. We thank too Dr. George Hunter for the bromide analyses and Dr. A. Spriggs for the cytoo logical examinations. We are very grateful to $\mathrm{Mr}$. Wylie McKissock, Mr. J. Pennybacker, and Mr. J. S. Calnaro for permission to refer to cases under their care. We alsothank Professor T. Crawford, Dr. D. Oppenheimer, Dr J. Protheroe, Dr. U. Rowlatt, and Dr. W. T. D. Richards̆ for permission to quote from their reports and for supplying tissue for histological examination. We arew 
indebted to Mrs. E. Courtnay for the photomicrographs. The necessary technical work was financed by a grant from the Nuffield Foundation to Professor P. M. Daniel, Institute of Psychiatry, London, S.E.5.

\section{REFERENCES}

Acheson, R. M., and Smith, H. V. (1958). Quart. J. Med., N.S. 27, 83. Berg, L. (1953). Neurology, 3, 811.

Fischer-Williams, M., Bosanquet, F. D., and Daniel, P. M. (1955). Brain, 78, 42.

Heathfield, K. W. G., and Williams, J. R. B., (1956). Brit. med. J., 1,328 .
Hunter, G., Smith, H. V., and Taylor, L. M. (1954). Biochem. J., 56, 588.

Marks, V., and Marrack, D. (1960). J. Neurol. Neurosurg. Psychiat., 23, 194.

McMenemey, W. H., and Cumings, J. N. (1959). J. clin. Path., 12, 400. Polmeteer, E. E., and Kernohan, J. W. (1947). Arch. Neurol. Psychiat. (Chic.), 57, 593.

Russell, D. S. (1939). Postgrad. med. J., 15, 150.

Smith, H. V., Taylor, L. M., and Hunter, G. (1955). J. Neurol. Neurosurg. Psychiat., 18, 237.

Spriggs, A. I. (1954). J. clin. Path., 7, 122.

Taylor, L. M., Smith, H. V., and Hunter, G. (1954). Lancet, 1, 700.

Taylor, K. B., Smith, H. V., and Vollum, R. L. (1955). J. Neurol. Neurosurg. Psychiat., 18, 165. 